\title{
APONTAMENTOS SOBRE A LITERATURA ITALIANA DOS ANOS 2000
}

\author{
Giuliana Benvenuti * \\ Tradução de Juliana WeXel
}

RESUMO: A literatura italiana dos anos 2000 parece ser caracterizada por um contato cada vez mais próximo com outras mídias, no interior daquela que é definida como sociedade pós-mídiática. Com base nas mudanças que ocorreram já a partir dos anos 1980, a contribuição indaga em um dos percursos menos investigados: o que se origina da colaboração entre romancistas e cartunistas e que, com frequência, se inscreve sob o signo do noir. As experiências do grupo Valvoline assim como a dos Cannibali parecem ser seminais de um emaranhado de linguagens destinado a continuar nas décadas seguintes, dentro de uma experimentação que, mesmo pouco estudada na crítica literária, segue até o presente global dos anos 2000.

PALAVRAS-CHAVE: Literatura italiana dos anos 2000; noir italiano; pulp italiano; Carlo Lucarelli; literatura e cultura visual.

ABSTRACT: La letteratura italiana degli anni Zero appare caratterizzata dal contatto sempre più ravvicinato con gli altri media, all'interno di quella che viene definita la società postmediale. Prendendo le mosse dalle modificazioni intervenute già a partire dagli anni Ottanta, il contributo indaga in uno dei percorsi meno indagati: quello che si origina dalla collaborazione tra romanzieri e fumettisti e che spesso si inscrive sotto il segno del noir. L'esperienza del gruppo Valvoline, così come quella dei Cannibali, appaiono seminali di un intreccio di linguaggi destinato a proseguire, nei decenni successivi, entro una sperimentazione che, poco studiata in sede di critica letteraria, prosegue sino al presente globale degli anni Zero.

PAROLE CHIAVE: Letteratura italiana degli anni Zero; noir italiano; pulp italiano; Carlo Lucarelli; letteratura e cultura visuale.

ABSTRACT: The Italian literature of the 2000s is characterized by an ever closer relation with other media. Starting from the changes occurred since the 1980 s, the contribution explores one of the less investigated pathways: the one that originates from the collaboration between novelists and cartoonists. The experiences of the Valvoline

*Università di Bologna - UNIBO - giuliana.benvenuti2@unibo.it

Juliana Wexel é jornalista, Mestre em Letras, Cultura e Regionalidade pela Universidade de Caxias do Sul (Brasil) e Leitora de Português Brasileiro na Escola de Línguas, Literatura, Tradução e Interpretação do Departamento de Línguas, Literaturas e Culturas Modernas (LILEC) da Universidade de Bolonha, na Itália.

DOI: http://dx.doi.org/10.11606/issn.2238-8281.v0i37p5-16 


$$
\square
$$




\section{Observações preliminares}

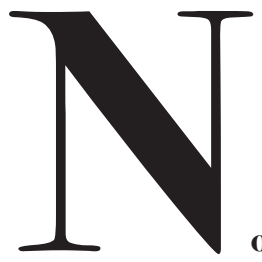

os últimos vinte anos, o debate crítico acerca da situação da literatura na Itália, bem como em outros países europeus, teve entre os seus eixos centrais o "perigo" representado pelo domínio de outras mídias e pelo progressivo distanciamento dos escritores da tradição literária nacional. É necessário prestar atenção não somente à transformação das mídias, mas também às complexas estratégias de transculturação implementadas, seja no momento da produção, seja no momento da recepção dos produtos culturais. O livro, por exemplo, passa a fazer parte de um novo ecossistema de leitura ${ }^{1}$ que o torna sempre mais "aberto" no nível da propriedade intelectual, também porque pode ser facilmente transportado de um suporte a outro e, em última análise, facilmente manipulável, exposto, como é, a múltiplas formas de reutilização, descontextualização e reapropriação.

A sociedade pós-mídia e a era global, em outras palavras, além de nos colocar diante de novos desafios, repropõem também, de maneira inédita, processos de transculturação e transmissão da tradição, criadores de novas diferenças. As reflexões mais recentes sobre a tradução e as relações entre as línguas propuseram uma abertura teórica à altura da complexidade das contínuas interações entre língua e cultura, sob a perspectiva de uma crítica ao monolinguismo como forma de descrição dos fenômenos linguísticos e comunicativos que não correspondem à proposição, segundo a qual estamos já desde sempre em tradução, isto é, imersos em fluxos de relações plurilinguísticas. Essas reflexões podem propor sugestivas analogias com o que acontece entre as mídias que cooperam com a criação de narrativas, entretêm as relações de refração, modificam o storytelling em relação ao contexto no qual isso se insere, dando lugar a complexos fenômenos de difusão, apropriação e transculturação dos textos.

1 Sobre a possibilidade de manipular os textos (dentro de uma interpretação da reescrita como forma de leitura de um texto), cfr. COSTA P. Il futuro del testo. L'esperienza della lettura nell'epoca postmediale. Milano: Egea, 2016 (em part. cap. II). 


\section{A década de 1990}

Os autores que estreiam no começo dos anos 1980, como Pier Vittorio Tondelli (Altri libertini, 1980), Enrico Palandri (Boccalone, 1979) ou Andrea De Carlo (Treno di panna, 1981), entre outros, ambientam seus romances em uma contemporaneidade livre de contato com o passado, invasiva e ao mesmo tempo exaltante, e que os faz parecer estrangeiros às angústias e à atormentada relação com a tradição literária (ao mesmo tempo sem utilidade e ainda influente) que marcava a escrita das obras de Pasolini, de Calvino, de Fortini ou dos neovanguardistas. Para eles, retornar aos gêneros literários significa, inevitavelmente, referir-se a uma tradição codificada, retomar mecanismos narrativos comprovados, aceitando regras e limites ditados justamente pelo gênero. Essas regras e limites podem ser impelidos, podem ser transgredidos, colocando o próprio gênero em questão. Os anos de 1980 e 1990, portanto, deram lugar a uma produção literária que parece dissipar as ansiedades e a nostalgia pertencentes à época anterior, levando ao texto literário referências cada vez mais abertas a uma realidade entrelaçada com a cultura visual, dos modelos cinematográficos e televisivos aos estereótipos do discurso publicitário e dos meios de comunicação de massa. Niccolò Ammaniti, por exemplo, declara sem hesitação que, para ele, a literatura é o último dos problemas, e que a relação com a tradição literária nacional, simplesmente, não lhe interessa. E em se tratando da própria relação com a nova vanguarda, isto é, a literatura dos precursores com a qual o diálogo dos Cannibali, como se sabe, está longe de estar suspenso, Tiziano Scarpa reitera a vitalidade das propostas alternativas de diretores e cartunistas, das quais ele se sente mais próximo como narrador do que da "cumplicidade maneirista" dos vanguardistas. E alguém, de fato, referiu-se a "pós-vanguarda" no que tange à Scarpa e colegas. (TURCHETTA, 2005, p. 10-17)

Esses escritores vivem num mundo de imaginários interconectados, onde a cultura midiática e as novas tecnologias exercem um papel decisivo. Para além da ideia do quanto os Cannibali realmente formam um grupo, de quanto essa combinação é uma estratégia de marketing mais do que uma ideia comum de literatura, esses escritores, se entendidos como uma galáxia geracional, são os primeiros a tecer visivelmente seus textos a partir de situações e citações que são claramente não-literárias, mas provenientes da cultura visual. Por outro lado, o gênero pulp, sob o qual esses escritores têm sido abordados pela crítica desde o início, remete a um universo que é, nem exclusivamente literário, nem nacional. De acordo com a definição de La Porta, "consideramos o pulp a produção literária, visual, etc., que atualmente utiliza ou recicla materiais "baratos", populares, ligados aos gêneros (ou quadrinhos ou de "apêndice": sólidos enredos, patologias elementares, sangue em abundância), mas com uma consciência ou com uma ironia que permitem sair da inerte serialidade do gênero". (LA PORTA, 1999, p. 261)

Assim, o pulp dos jovens iniciantes, de Niccolò Ammaniti a Aldo Nove, unidos pela tanto afortunada quanto problemática definição de "canibais", encarna o momento de transição que ocorre na segunda metade da década, quando a maior publicação promove alguns escritores, 
na onda do sucesso da experiência da Editora Einaudi da série "Stile libero". "Stile libero" impõe a um público mais amplo a ideia de um noir sem limites com Gioventù cannibale, a então famosa coleção com curadoria de Daniele Brolli em 1996 que, no subtítulo, declara-se a primeira antologia italiana de horror extremo. Outros editores seguirão o exemplo da Einaudi e os catálogos estarão repletos de histórias e romances pulp e noir, tomando para si, não sem polêmicas, autores e títulos da pequena e média editora que, primeiramente, havia dado crédito aos jovens iniciantes. Ao mesmo tempo, esses jovens escritores irão se voltar, cada vez mais, a um imaginário não apenas literário. A sua cultura será cada vez mais imbuída de referenciais e modelos oriundos do cinema, da televisão, dos quadrinhos, dos desenhos animados, da música, do audiovisual, etc. A mesma construção do personagem de romance é adaptada para incorporar partes da cultura midiática, privilegiando a parafernália pop que se estabeleceu nos anos 80 , aos instrumentos da tradição.

Entre as possíveis referências há o grupo Valvoline, por exemplo, que nasce em Bolonha, em 1983. Composto, entre outros, por Scozzari, Igort e Mattotti, tem raízes culturais muito semelhantes às dos cannibali Aldo Nove, Niccolò Ammaniti, Tiziano Scarpa, que de fato megulham na iconografia pop e têm nos quadrinhos um elo de ligação muito importante. $\mathrm{O}$ projeto de Valvoline era o de reinventar os velhos gêneros de narrativa e fazer deles um objeto moderno. Absorver o pop e o pulp, o noir e as crime stories, o fantástico e o exótico: tudo isso transformado em novas narrativas, deslocadas das vias da "alta cultura".

É o caso aqui de apenas mencionar a parcial exceção constituída pela escrita de Tiziano Scarpa, na amostra ideal do que é um outro marco de 1996, o romance Occhi sulla graticola. Aqui, estilo clássico e tradição popular coexistem descaradamente de forma fetichizada: da sátira menipeiaª̀ Dostoiévski, da body art à pornografia dos mangás (por sua vez, Scarpa roteiriza histórias em quadrinhos para "Frigidaire" ou volumes independentes, em colaboração com ilustradores, designers e cartunistas entre os mais conhecidos).

\section{Em direção aos anos 2000}

A partir dos anos 90, na Itália houve, paralelamente, uma verdadeira explosão de textos que podemos considerar noir: a ficção italiana foi atingida por uma maré incontrolável de rótulos variados, que tentavam redefinir histórias baseadas no espaço "elástico" da literatura de gênero noir. Essa variedade deu origem a um número considerável de intervenções críticas, destinadas a distinguir o noir italiano do hard boiled, do mistery, do crime, do thriller, do roman policier francês e do Kriminal Roman alemão. Enquanto, junto às teorias da transculturlidade, manifestam-se os pontos de vista dos codificadores de instâncias homologadoras por parte da indústria cultural global, pelos quais, de acordo com Coletti, "As exigências do gênero prevalecem sobre a sensibilidade das diferentes culturas literárias e sociopolíticas. A literatura de massa é ligada

2 Cfr. LAGO, P. Una satira menippea a Venezia: una lettura di "Occhi sulla graticola" di Tiziano Scarpa. In Studi novecenteschi, XXXVI, n. 78, 2009, p. 419-430. 
ao mundo. Até mesmo os gialli pertencem a esse cânone. As histórias seriam as mesmas se acontecessem em outros lugares [...]. Os reagentes locais adquirem a força dos elementos diferenciais e definidores, muito explorados pelo mercado. Mas não essenciais." É sem razão, então? (COLETTI, 2011, p. 81-82)

O primeiro dado a se ter em mente é de que se trata de um sucesso sem precedentes em termos de número de textos publicados e de vendas. Um real e verdadeiro boom é o que as cifras demonstram: o mercado dos romances gialli e noir aumentou $460 \%$ entre os anos de 1994 e 2003; dentro dessa produção, o número de autores italianos aumentou 1.700\%. Os dados referem-se apenas aos livros vendidos em livrarias, excluindo a distribuição nas bancas, nas quais muitas também vendem coleções como Urania, Segretissimo, Gialli Mondadori. Finalmente, uma pesquisa de 2010 confirma a tendência, indicando, todavia, um crescimento ainda maior. (MONDELLO, 2015)

Os escritores em cena - o segundo aspecto importante - pertencem a uma geração na qual o formato do livro não é mais autossuficiente, tendo se tornado parte de um circuito comunicativo mais amplo, que vê a literatura cooperar com as outras mídias e tem na rede seu ponto de interação coletiva. A relação entre mídia pode ser descrita como uma série de operações contínuas de observação, reprodução e substituição recíprocas. A remediação, portanto, intercepta as práticas de adaptação, no sentido vital e atualizado, que Linda Hutcheon atribui ao termo. Hutcheon (2011, p. 38) sublinha como a adaptação é uma transposição declarada de outro texto, uma forma de repetição sem duplicação. Ao referir-se a uma transposição, é bom ter em mente duas perspectivas conectadas: o processo e o produto. Uma adaptação é, ao mesmo tempo, um processo de interpretação que, muitas vezes, implica num trabalho de subtração e redução, e um produto que, através de uma livre reinterpretação, retoma certos passos em um sistema semiótico diferente, tornando-o, simultaneamente, um texto autônomo. Do lado crítico, trata-se, portanto, de identificar os processos pelos quais os autores e usuários fizeram a negociação entre diferentes mídias e culturas progredir, realizando uma pesquisa fascinante: aquela que leva a distinguir e quase a diferenciar, um a um, os diferentes circuitos da comunicação que, cronológica ou geograficamente, se cruzam e acabam formando, desse modo, o feixe do discurso social e da cultural global. Do lado da produção, por sua vez, é uma questão de implementar estratégias de transculturação, para alcançar um mercado potencialmente global. Os conteúdos se fragmentam, os textos, considerados singularmente, são independentes e conectados e, finalmente, não há um texto proeminente, portador do sentido geral da narração, embora todo texto seja concebido como coerente e autônomo em relação aos demais. (DAMROSCH, 2008, p. 485)

Um gênero de sucesso global como o noir, se presta, mesmo na específica declinação do noir ao modo italiano, a ser vendido no exterior, a se tornar um sucesso mundial. Em suma, na Itália, as narrativas de sucesso internacional surgem principalmente dentro do noir e/ou de um gênero relacionado, o gênero da distopia do pós-apocalíptico. Se estas são as modalidades narrativas dominantes, aparecem três tipologias preferenciais: narrativas que exploram estraté- 
gias glocais, como é o caso de Gomorra e de toda a cadeia transmídia que dá vida ao romance de Roberto Saviano; narrativas "exóticas", nas quais o elemento de alteridade é confiado, em especial, à linguagem, como nas obras de Andrea Camilleri; finalmente, operações como as de Giancarlo De Cataldo e Carlo Lucarelli, que fazem uma releitura da história e da imprensa italianas, sobretudo através dos filtros do noir e do giallo $^{3}$.

Uma parte desse sucesso deve-se, de fato, à vontade dos escritores de revelar a Itália em seus aspectos mais obscuros e problemáticos, através de um gênero popular. Mas isso apresenta-se exibindo um conjunto de textos com características tão diferentes, que sugerem que o noir é um rótulo comercial que combina contos históricos, de revelação, de estrutura social e política e, até mesmo, de testemunhos e denúncias. O fator em comum, em meio a tanta diversidade, é tratar-se de histórias italianas. Os personagens são italianos e, muitas vezes, os cenários e os crimes são baseados na história e na imprensa nacional italianas. No período anterior à década de 90 , os poucos giallisti e noiristi italianos, em geral sob pseudônimo, escreviam histórias que se passavam em outros lugares: assim, os assassinos e suas vítimas acabavam tendo, muitas vezes, a generalidade anglo-saxônica, satisfazendo a xenofobia dos fãs.

A partir dessas experiências, no entanto, rapidamente ganha vida uma forma de narrativa noir que se apresenta, como mencionado, muito italiana (por autores, cenários, enredos, personagens), declinando de histórias brutais de serial killers, alienados mentais, psicopatas, borderlines que se movem com inaudita e gratuita crueldade nas atmosferas metropolitanas das cidades do norte do país, mas não só, como também centros evidentes e definidos da geografia literária do noir italiano. (MONDELLO, 2015) De fato, por iniciativa de Andrea G. Pinketts, surge em 1993, em Milão, a Scuola dei duri, um grupo de escritores que dá vida à antologia Crimine. Milano giallo-nera. Em 1994, em Roma, o grupo Neonoir, composto por escritores, críticos e diretores, começa a produzir, individual e coletivamente, textos narrativos, teatrais e radiofônicos. O grande expoente é Dario Argento, graças a quem se assume a ideia de uma escrita que evidencie o ponto de vista do assassino. Em Bolonha, no entanto, nasce o Gruppo 13, formado inicialmente por Loriano Machiavelli, Pino Cacucci, Massimo Carloni, Nicola Ciccoli, Danila Comastri Montanari, Marcello Fois, Carlo Lucarelli, Lorenzo Marzaduri, Loriano Macchiavelli, Gianni Materazzo, Sandro Toni e dois ilustradores: Claudio Lanzoni e Mannes Laffi. O primeiro trabalho em comum que aparece nas livrarias é uma coletânea de contos, $I$ delitti del Gruppo 13 (Metrolibri, 1991, s/p), em cuja contracapa, lemos:

O crime espalha-se em Bolonha. Os disparos ecoam sob os pórticos, morrese à sombra das torres. E Marlowe fala agora com um sotaque emiliano. Será uma coincidência que escritores do gênero gialli proliferem em Bolonha e arredores? Eles são tantos, destemidos, organizados. Até criaram uma irmandade: o Gruppo 13, que inclui dez escritores e dois ilustradores. Essa antologia representa o primeiro compromisso coletivo deles: dez histórias inéditas, todas convincentes, todas ilustradas. O que une estes

3 Livro ou romance giallo é um tipo de romance policial muito popular (chamado assim na Itália porque a partir da década de 1930 esse gênero geralmente era publicado em volumes de capa amarela, livro "giallo" justamente) que mantém alto o interesse do leitor com a narração de crimes misteriosos e episódios imprevistos, sensacionais; deriva daí, também, o uso de expressões como: conto giallo, drama giallo, film giallo. N.d.E. 
autores, além da "bolonhesidade" e indiscutível talento? Certamente o clima cultural comum: o de uma cidade prolífica e vibrante que já soube expressar fenômenos importantes, como uma grande escola de quadrinhos. À qual pertencem, a propósito, os magníficos ilustradores das histórias apresentadas aqui. (MOSCATI, 1991, s/p)

Ainda uma rota intermediária para marcar o caminho da experimentação. Cerca de dez anos depois, na verdade, a emancipação da chamada paraliteratura foi plenamente consumada: por volta de 2005, o boom ' giallo-noir' é um dado adquirido, enquanto a expansão desse mercado continua, ainda, espalhando-se na serialidade televisiva. É a prova, em termos de classificações, da progressiva aprovação do noir como uma forma capaz de realçar a realidade da Itália de hoje, ligada à história recente dos anos de 1970, ao nascimento da segunda República. O noir, então, reúne o legado do realismo, definindo-se como uma prática de denúncia. De Cataldo, Lucarelli, Carlotto, entre outros, argumentam que o noir é capaz de representar a sociedade contemporânea melhor do que qualquer outra forma. Uma forte natureza política é, de fato, atribuída ao ato de narrar de uma maneira antagonista ou, incompatível com o do mainstream literário, buscando, através do gesto criativo de "outra" escrita, uma função ideológica do texto e do papel intelectual do autor.

Entre os elementos mais notáveis do noir italiano contemporâneo, destacam-se a fúria horrenda, a crueldade e o horror das descrições e a ambientação das histórias nas metrópoles de uma Itália vista como espaço de conflitos sociais, de solidões inquietantes que conduzem à desumanidade e à selvageria. Isto ocorre porque o noir recusa uma construção que autodefina os limites de uma estrutura coerciva: não pressupõe qualquer "final feliz" e não aceita fronteiras entre o bem e o mal. Não tende a tranquilizar o leitor com a identificação do culpado, mas o conduz pela mão no universo perturbador e angustiante de um real que existe na sociedade, embora tenda-se a exorcizá-lo.

Para essa configuração, a escrita noir está contaminada com a modalidade distópica: o mal não reside em algum "outro lugar", mas se esconde no lado escuro da normalidade. Os ambientes, as ruas, as atmosferas metropolitanas desenham uma zona limite onde se oculta um sistema sociocultural anômalo, ao qual corresponde uma nova antropologia. É um território devastado pela "aldeia global", um lugar onde a mídia distorceu as relações humanas e confundiu a realidade objetiva com a ficção. Se o formato televisivo do ano continua sendo o Grande Fratello ${ }^{4}$, o célebre reality show do Canale5, eis que surge o neonoir intitulado Grande macello (2001), por iniciativa do grupo romano e da editora Stampa Alternativa. A antologia (os autores: Marco Minicangeli, Marco Vallarono, Ivo Scanner, Monica Margotti, Alda Teodorani, Gaetano Ristretta, Luigi Boccia, Nicola Lombardi, Stefano Bovi e Dominick Mason) reúne histórias selecionadas a partir de espaços de escrita criativa online, enquanto a rede e as práticas interativas já ditam novas leis ao mercado cultural. Na capa, um olho cheio de agulhas cita o filme Opera de Dario Argento, numa irônica mutação do logotipo do programa (o olho da câmera onisciente

4 Corresponde ao idêntico formato televisivo do reality show BBB, Big Brother Brasil, da Rede Globo de Televisão, N.d.T. 
que espiona os protagonistas trancados na "casa"), a revelar que tal programa "é a transmissão mais sádica e violenta da história da televisão". (GIOVANNINI, 2001, p. 3) Percorrendo outros caminhos que não o tradicional "compromisso" dos intelectuais, no qual configura-se historicamente o século XX e experimentando um cânone narrativo que, à primeira vista, parece introspectivo e repleto de psicologismo, a literatura neonoir também atribui-se uma função político-ideológica. O grupo reivindica, em diversos lugares, uma posição "militante” própria, significando com esse termo a afirmação de um status intelectual comprometido e/ou antagonista e a proposição de problemas dramaticamente reais por meio do noir.

\section{Os anos 2000: o caso Lucarelli}

A estreia literária de Carlo Lucarelli acontece com o giallo 'Carta bianca' (1990), o primeiro de uma longa série de noir de cunho policial. Ativo desde o início dos anos 90, ele publicou, até hoje, romances, contos, ensaios e foi diretor, roteirista e apresentador de programas de televisão. $\mathrm{O}$ autor caracteriza-se, desde o início, pela extrema consistência temática e de abordagem, com uma grande versatilidade realizadora: para a TV é, de fato, apresentador do programa Blu notte, no ar desde 1998, e para os quadrinhos assinou o argumento n. 153 de Dylan Dog (La strada verso il nulla). O traço de união que liga sua vasta experiência literária é dado por uma amálgama entre noir, giallo e crime fiction em todas as declinações. (GIOVANETTI, 2005)

Também é significativa a rede de suas colaborações com especialistas - criminalistas, autoridades policiais, magistrados, repórteres sensacionalistas -, que se amplia com as produções televisivas, em particular, do programa Blu notte, que analisa de maneira aprofundada as notícias, investigações sobre desastres e assassinatos em série dos últimos 50 anos da história italiana. Para narrar Misteri Italiani - subtítulo do formato - o autor se vale de uma série de topoi que retira diretamente de seus romances policiais: uma polícia, em muitos casos, indiferente; suspeitos de moralidade duvidosa e mortos em circunstâncias misteriosas; insuspeitos, os quais descobre-se serem culpados. É o vasto modelo apreciado pelos teóricos da conspiração. Mas Lucarelli sempre se detém antes de indicar um plano abrangente e perfeito, o que representaria sua entrada no vórtice da paranoia pós-moderna. De fato, os planos sintetizados por Lucarelli nunca são perfeitos: há sempre uma testemunha que, no final, relata, um detetive que descobre algo, um rastro ou uma pista, ainda que a verdade permaneça sempre oculta. A ausência de culpados e mandantes, que emerge dos segmentos tanto televisivos quanto dos literários, é mais do que um artifício retórico: é um aspecto irredutível da sociedade italiana, o que leva à denúncia de um sistema investigativo altamente condicionado, muitas vezes precipitado e sempre ostentado por muitos lados.

À atividade de apresentador desenvolve-se paralela e concomitantentemente, a de crítico, através da qual Lucarelli fornece a sua interpretação do desenvolvimento do noir e sua posição dentro do gênero: de fato, ele afirma ter sido, no início da sua carreira como romancista, 
seguidor da linha Chandler-Scerbanenco, ainda centrada nos desenvolvimentos narrativos que conduzem à solução de um crime. Aos poucos, esse elemento tornou-se menos importante para ele: a representação do mundo do crime surge como uma prioridade no que diz respeito à descoberta do criminoso. Adentra-se, assim, no território do noir, definido por Lucarelli como a história da "metade obscura das coisas que acontecem." (BERNARDI; LUCARELLI, 2010, p. 219)

Entre os romances de Lucarelli mais lidos e traduzidos no exterior, Almost blue (1997) é o que mais se aproxima da experiência da supracitada Gioventù cannibale, a antologia de 1996 que reúne textos de "horror extremo". O autor não participa diretamente dela, mas o contexto no qual as duas obras se desenvolvem é análogo: é clara a influência do romance-verdade ao estilo Truman Capote (romance de não-ficção). Almost blue se tornará, então, um filme, transportado para a grande tela por Alex Infascelli, em 2000.

Se a experiência como polígrafo não o diferencia completamente de uma obra de Scarpa e dos outros nomes mencionados naquele movimento, é sua característica única ser parte integrante dos primeiros casos italianos de narrativas transmídia. Um exemplo: o personagem do inspetor Coliandro, depois de aparecer na história de Nikita (pela já citada antologia I delitti del Gruppo 13), foi então protagonista de dois romances posteriores de Lucarelli, originalmente publicados pela Granata Press: Falange armata em 1993 e Il giorno del lupo em 1994 (ambos reeditados pela Editora Einaudi na ordem inversa). Os acontecimentos de Falange armata são inspirados na história da famigerada gangue de 'Uno bianca' e descrevem um Coliandro irritadiço, que se comporta às vezes como um Rambo provinciano, desajeitado e descuidado, mas que investiga na direção certa. É curioso que, em janeiro de 1993, quando o livro é publicado, o caso da 'Uno bianca' ainda não esteja resolvido. Coliandro percebe que a delegacia de polícia de Bolonha está implicada nos assassinatos, com uma intuição que, então, foi confirmada na realidade.

Em outubro de 2009 - para sublinhar a atenção que o mercado editorial começa a prestar aos casos midiáticos - a trilogia completa de Lucarelli foi publicada pela Editora Einaudi em um único volume, intitulado L'ispettore Coliandro, que mostra na capa a foto de Giampaolo Morelli na versão televisiva do personagem. L'ispettore Coliandro é, precisamente, também o título da série de TV exibida desde 2006 pela Rai 2, e desde 2017 pela Rai Play. A operação não é isolada: entre 2008 e 2010, teve lugar a realização de Cornelio - Delitti d'autore (Star Comics), uma história em quadrinhos de terror e noir. A série leva o nome do seu protagonista, um escritor de noir em um estado de forte crise criativa. O escritor tem os traços do próprio Lucarelli, autor da história em quadrinhos juntamente com Mauro Smocovich e Giuseppe Di Bernardo. 


\section{Conclusão}

Se olharmos, então, para o final do século XX a partir dessa perspectiva, descobrimos que a experimentação das intersecções entre culturas e mídia nos anos 2000 houve interessantes precedentes nos últimos vinte anos, os quais essa intervenção sintetiza. Isto é, nasce nos anos de 1970 na Itália, uma experimentação que, menos estudada pela crítica literária, atravessa os anos de 1980 e 1990 para, depois, continuar nos chamados anos 2000 e que vê, primeiramente, na mistura entre quadrinhos e literatura, um importante fator de transformação de um e de outro, e a formação de um terreno comum, feito de relações, trocas e colaborações entre autores. Um terreno no qual irão convergir, então, outros exemplos da cultura visual e da mídia de massa. A experimentação surge, por assim dizer, do retrato da vanguarda e se torna pop, explorando também as potencialidades da tecnologia digital. É à luz dessas transformações que, talvez, deva ser revista a história literária italiana dos últimos 30 / 40 anos. 


\section{Referèncias}

BERNARDI L., LUCARELLI C. Senza rete: le metamorfosi del giallo italiano viste dall'interno. In DE PAULIS-DALAMBERT, M. P. (org.) L'italie en Jaune et Noir: la littérature policière de 1990 à nos jours. Paris: Presses Sorbonne Nouvelle, 2010, p. 215-220.

BROLLI, D. (org.) Gioventù cannibale: la prima antologia italiana dell'orrore estremo. Torino: Einaudi, 1996.

COLETTI V. Romanzo mondo: la letteratura nel villaggio globale. Bologna: Il Mulino, 2011.

COSTA P. Il futuro del testo. L'esperienza della lettura nell'epoca postmediale. Milano: Egea, 2016.

DAMROSCH D. Toward a History of World Literature. In: New Literary History. Johns Hopkins niversity Press. Vol. 39, no 3, summer 2008, p. 481-495. Disponível em: https://muse.jhu.edu/article/259608. Acesso: 26/06/2017.

DE CARLO, A. Treno di panna. Torino: Einaudi, 1981.

GIOVANNETTI P. (org) Almost noir. Indagini non autorizzate su Carlo Lucarelli. Milano: Arcipelago Edizioni, 2005.

GIOVANNINI. F. Premessa. In: __. Grande macello: racconti di horror estremo. Viterbo: Millelire Stampa Alternativa, 2001, p. 3-4

HUTCHEONL. Teoria degli adattamenti: ipercorsi delle storie fra letteratura, cinema, nuovi media. Roma: Armando, 2011.

LAGO, P. Una satira menippea a Venezia: una lettura di "Occhi sulla graticola" di Tiziano Scarpa. Studi novecenteschi, XXXVI, n. 78, 2009, p. 419-430.

LA PORTA F. La nuova narrativa italiana: travestimenti e stili di fine secolo. Torino: Bollati Boringhieri, 1999.

LUCARELLI C. L'ispettore Coliandro. Torino: Einaudi, 2016. . Almost blue. Torino: Einaudi, 1997.

. Il giorno del lupo. Bologna: Granata, 1994.

. Falange armata. Bologna: Metrolibri, 1993.

. Carta bianca. Palermo: Sellerio, 1990.

MONDELLO E. Il noir degli anni Zero: uno sguardo sulla narrativa italiana del terzo millennio. Roma: Perrone Editore, 2015.

MOSCATI, M. (org.) I delitti del gruppo 13: antologia illustrata dei giallisti bolognesi Bologna: Metrolibri, 1991, quarta capa.

SCARPA, T. Occhi sulla graticola. Torino: Einaudi, 1996.

TONDELLI, P. V. Altri libertini. Milano: Feltrinelli, 1980.

TURCHETTA G. I Cannibali non mordono più. In: SPINAZZOLA, V. (org.) Tirature '05. Giovani scrittori e personaggi giovani. Milano: II saggiatore, 2005, p. 10-17.

Recebido: 20/06/2018

Aprovado: 04/10/2018 